\section{Anamnesis de una estructura. La Catedral de Vitoria entre los siglos XII y XX}

\author{
Leandro Cámara Muñoz, Pablo Latorre González-Moro \\ Latorre y Cámara, S.L.
}

\begin{abstract}
Resumen
La Catedral de Vitoria es un edificio con una larga vida histórica, llena de acontecimientos constructivos que han venido interesando su comportamiento como estructura construida. Ha sido un objetivo primordial del Plan Director evaluar las sucesivas consecuencias de todos esos acontecimientos y explicar su concatenación. Todo ello se ha investigado durante su redacción, consiguiendo una secuencia cronológica en la que se relaciona el conjunto de intervenciones y de "proyectos" arquitectónicos que se suceden desde el comienzo de la construcción de la iglesia en los inicios del siglo XIII hasta sus últimas restauraciones en los años 60 del siglo XX. Este estudio histórico tiene una aplicación directa en la interpretación de los problemas estructurales que presenta el edificio y viene a llenar un vacío de información fundamental para la evaluación de la seguridad y perdurabilidad actuales de la Catedral.

Esa historia de la Catedral viene a ser la recuperación del "historial médico" de un enfermo y puede dar muchas claves sobre los problemas estructurales que en otros apartados del mismo se detallan. La "anamnesis" practicada sobre el monumento es una de las "piedras de toque" del método elegido por nosotros para la restauración del conjunto catedralicio, no sólo en el tema estructural que interesa en esta ponencia sino en todos los problemas de interpretación funcional y contenido simbólico a los que hay que dar solución con las propuestas del restauración.

La lectura de esa historia constructiva en clave de análisis estructural es lo que en esta ponencia se presenta: la extracción de la secuencia histórica constructiva que conduce al estado actual del edificio, discriminando los distintos momentos de proyecto arquitectónico, fases de crecimiento constructivo del edificio e intervenciones de reparación de la estructura que se explican o contradicen unos a otros para dar como resultado la torturada forma arquitectónica que nos encontramos ahora.

A partir de esa secuencia se evalúa, en parte, el estado de seguridad remanente de la estructura, y se hace una hipótesis de trabajo para las tareas de restauración en esos aspectos estructurales.
\end{abstract}

Palabras claves: Anamnesis, Restauración, Análisis estructural.

\section{Abstract}

The Cathedral of Vitoria is a building with an extended historical life. We have attempted to produce a chronological sequence of the interventions and architectural "projects" since the beginning of the construction of the church on the early XIIIth century to the last restorations during the 1960s. This study attempts to fill a void on the available information, crucial for the evaluation of safety and durability issues on the Cathedral.

The "anamnesis" praticed on the monument is one of the cornerstones of the method we have chosen for restoration, not only regarding the structural aspects, but regarding the problems of functional interpretation and symbolic content as well.

This historical reading the key of structural analysis is what we intend to present: the extraction of the historical building sequence that leads to the current situation of the building, discriminating the different moments of the architectural project, phases of buildimg growth and repair interventions on the structure that comment on or contradict among themselves, to result in the form that we witness now.

We use that sequence to evaluate, albeit partially, the safety status of the structure, and to build a working hypothesis for the structural aspects of the restoration tasks.

Key words: Anamnesis, Restoration, Structural Analysis.

\section{INTRODUCCIÓN}

\section{La memoria de los edificios}

Nuestros edificios antiguos recuerdan en su construcción todo lo que fueron antes de llegar a nosotros; retienen en sus formas y materiales, torturados o embellecidos por las generaciones pasadas, la crónica de sus avatares. La Catedral de Santa María de Vitoria también recuerda, a quien sepa prestar atención, la larga sucesión de lesiones, movimientos, asientos, problemas que, en definitiva, ha padecido; y lo que hicieron sus dueños para repararla y mantenerla en pie, convencidos como estarían de la bondad de su pervivencia. En esta comunicación trataremos de leer esa crónica desde un punto de vista muy concreto, el de los técnicos comprometidos en la recuperación de una estabilidad de las fábricas aparentemente perdida. Haremos una lectura diacrónica de algunos de los problemas estructurales que parece tener esta Catedral, ahora mismo sumida en una restauración de largo alcance.

\section{La teoría de estados límite aplicada a las estructuras de fábrica}

Nuestra presentación se va a guiar por una serie de consideraciones de cálculo y de evaluación de la seguridad del edificio que, como se verá, finalmente encuentran en la recuperación de la memoria perdida el indicio concluyente sobre la seguridad de la construcción.

Adelantaremos brevemente unas nociones sobre el tipo de análisis estructural que aplicaremos (fig. 1). Hoy día, el moderno proyectista de estructuras, siguiendo los códigos de cálculo al uso, establecerá que una estructura está correctamente dimensionada comparando las deformaciones que se espera padezca con unos límites empíricamente establecidos, en función de la utilidad concreta que haya de darse al edificio. Sin embargo, este criterio no es válido para las estructuras ya existentes: en primer lugar, porque sus deformaciones vendrán ya dadas por siglos de interacción con la naturaleza y con los propios usuarios, haciendo ahora imposible su vuelta atrás, al menos en la mayoría de los casos; y en segundo lugar, lo más importante, porque es casi imposible predecir de qué manera se va a deformar una estructura de fábrica. Se trata de construcciones con un altísimo grado de hiperestaticidad, lo que significa que su comportamiento depende de infinidad de variables cuyos "valores" en un momento dado son casi imposibles de establecer. La moderna teoría de los estados límites - por cierto, también aplicable a las estructuras de nueva construcción- viene a ayudarnos a establecer algunos criterios que nos permitan confiar en la estabilidad y seguridad del edificio. Si partimos de esa consideración de 
la complejidad de las estructuras, deberemos conformarnos con encontrar al menos un estado de equilibrio entre la estructura y las cargas aplicadas que mantenga los esfuerzos en las fábricas dentro de unos márgenes tolerables por ellas. Veremos algunos ejemplos más adelante.

Además, tendremos que aceptar que nuestro estado de equilibrio no será, en ningún caso, el real de la estructura en ningún momento de su existencia. Lo cual no es preocupante si hablamos de una estructura en pie, pues el hecho de que se sostenga ahora mismo quiere decir que ha pasado con éxito la prueba de su estabilidad, al descimbrarla y dejarla en el aire. En ese momento, y en todos los posteriores, ha venido encontrando infinitos y sucesivos estados de equilibrio similares al que nosotros podemos encontrar teóricamente.

\section{La Catedral de Vitoria.}

En la revisión de la Catedral que ahora haremos llegaremos a este punto en muchas ocasiones. Más allá no habría más que la inútil pretensión de que conocemos todas las variables y somos capaces de determinar su interacción exacta.

\section{Aplicación de la teoría plástica. El testigo-cero de la anterior restauración}

Los arcos son un grandioso invento de la humanidad: nos permiten abrir grandes espacios para nuestra utilidad empleando pequeñas porciones de material constructivo que podemos manejar con nuestra escasa fuerza física (fig. 2). La estabilidad de un arco -o de una bóveda- se basa en la posibilidad de transmitir los pesos de esas piezas, de unas a otras, por un contacto físico, aunque éste sea muy pequeño. Volviendo a la teoría convencional de las estructuras, ese mínimo contacto, que se muestra en los gráficos de Frezier-Danizy - de la primera mitad del siglo XVIII-, supondría, en el límite, una concentración puntual de esfuerzos infinitos, lo que implicaría el aplastamiento del material y el fallo de la estructura. Sin embargo, todas las estructuras arcuadas muestran ese comportamiento. Las tres imágenes inferiores pertenecen a arcos de la Catedral de Vitoria y lo demuestran: en el arranque de los arcos, el giro del muro ha provocado la aparición de una rótula, es decir, de un punto de plastificación del material y giro libre de la estructura, correspondiente al punto $\mathrm{F}$ de los gráficos; más arriba, en el tramo medio de las ojivas y de los perpiaños, aparecen otras rótulas en el trasdós, no visibles desde aquí aunque manifiestas en la apertura de las juntas entre las dovelas -esto corresponde a los puntos I-S de los gráficos-. En este punto es interesante observar cómo el edificio mantiene un pertinaz pulso con los restauradores: donde éstos reparan una junta abierta cosiendo las dovelas con grapas metálicas, el arco sigue su camino y se vuelve a abrir en las juntas contiguas. Esto sólo significa que el arco necesita formar esas rótulas para resistir sus cargas en esa posición dada por los apoyos, pero no indica que tenga una mayor tendencia a la ruina. En el límite de la disputa podríamos arruinar el arco si nos empeñamos en reforzarlo en todas sus juntas, pues le conferiríamos un monolitismo que le obligaría a trabajar a flexión, para lo que no está preparado.

Esas grapas, así como el rejuntado de las dovelas y el estucado de los plementos, se deben a la restauración efectuada en los años sesenta del siglo pasado por el arquitecto José Manuel Lorente Junquera. De esta obra hablaremos más en los próximos análisis, pero ahora diremos que tiene para nosotros un significado muy especial, al haber establecido un testigo "cero" en la evolución de las grietas de la estructura. La reparación de todas las que entonces aparecían en el edificio nos permite ahora saber dónde éste se ha movido durante los últimos años para buscar un reacomodo a esa última modificación de sus condiciones de cargas y resistencias.

\section{Estado de agrietamiento y deformaciones detectadas} El crucero norte. Y según ese testigo, es fundamentalmente el transepto de la Catedral el que no consigue estabilizarse (fig. 3). En el alzado oriental de la nave de crucero se han marcado las grietas que han aparecido desde entonces, situadas en la esquina noroeste: donde la pilastra encastrada en el muro norte -izquierda de la foto- se desgaja netamente del muro de levante; y donde éste mismo muro se abre y se separa de los plementos de las bóvedas en el encastre de éstas sobre los arcos formeros. Luego veremos que también en el brazo sur se produce algo similar, incluso más grave.

La nave norte y las capillas abiertas. En la nave norte de la iglesia y en las capillas del transepto norte podemos ver ahora las grietas que se restañaron en la obra de los años sesenta (fig. 4). Hay que decir -y lo veremos luego- que lo que se muestra en estas fotos no se había vuelto a manifestar desde aquella obra y que ha sido nuestra investigación arqueológica y estructural la que ha "recuperado" las grietas para apreciar el estado en que se encontraba el edificio antes de aquella restauración, si bien, como veremos, no todo es atribuible a esa obra: la grieta sobre la capilla de santa Victoria, en la foto izquierda, ya estaba congelada tiempo antes. Más adelante explicaremos cuándo creemos que se reparó. 
La deformación de las naves altas: central y norte y sur del transepto. Cuando entramos por primera vez en la Catedral, nos llama poderosamente la atención la enorme magnitud de las deformaciones que ha acumulado a lo largo de su historia. Situándonos en el triforio podemos apreciar cómo se inclinan las pilastras de los tramos altos de las naves, tanto en la nave mayor como en el transepto. Estas deformaciones son observadas con nuevos ojos por cada técnico que se ocupa de la restauración de la Catedral, y tienen un efecto casi embriagador sobre él, que le asusta y lleva a querer poner toda clase de remedios estructurales. Son el extraño canto de sirenas de este edificio que, en el curso de los siglos, ha venido obligando a los arquitectos a añadir refuerzos, unos sobre otros, con mayor o menor fortuna pero, como veremos, casi siempre sin auténtica necesidad.

\section{Deformaciones padecidas}

En nuestro estudio de la Catedral hemos analizado estas deformaciones exhaustivamente antes de tratar de explicar qué significaban. A partir de la restitución fotogramétrica completa y en tres dimensiones, hemos ido obteniendo un gráfico para cada arco ojivo o perpiaño de la Catedral -los que salvan el gran vano de nueve metros de las naves que forman la gran cruz latina de su planta- (fig. 5). Aquí mostramos los correspondientes a los perpiaños de las naves norte -arriba- y sur -abajo- del transepto. En cada gráfico se muestra el dibujo fotogramétrico del alzado y un esquema de la deformada en el que se señalan con pequeños vectores los movimientos padecidos, que llegan a ser de treinta centímetros en toda la altura, con parciales de hasta casi cincuenta en el tramo comprendido entre el triforio y el arranque de los arcos perpiaños. En resumen, el análisis completo nos da un cuadro de los desplazamientos de esos puntos en toda la Catedral, que mostramos sobre una planta general (fig. 6). Se aprecian cinco grandes movimientos: en primer lugar, el ya mostrado de la esquina noreste del transepto, con una doble componente de apertura de la nave hacia el exterior y de resquebrajamiento de la esquina; en segundo lugar, otro desplazamiento de la misma nave norte del transepto en su muro occidental, también muy desplomado hacia el exterior; también en el transepto se aprecia una componente general de desplazamiento de todos los pilares hacia el norte, como cayendo ladera abajo desde lo alto del cerro de Gasteiz en que nos encontramos; en la nave central se da una apertura hacia el norte en los tramos cuarto y quinto; y por último, el punto aparentemente más inestable es el del machón situado al norte de la portada de Santa Ana, en el lado de poniente de la nave sur del transepto, que luego estudiamos con más detalle.

6. Los movimientos de la estructura. Contamos con un sistema de control continuo de los movimientos del edificio, formado por un conjunto de medidores de la apertura y cierre de las grietas, así como de la inclinación y separación relativa de los muros (fig. 7). Cada cierto tiempo -unas cuatro veces al día- estos aparatos miden el estado de la grieta o el muro y registran el dato para formar un gráfico que, en un periodo de cuatro años, nos muestra la tendencia evolutiva de cada lesión así controlada.

Noción de movimiento. Sin embargo, todos los edificios se mueven por efecto de los cambios de temperatura ambiental, siguiendo ciclos diarios - noche y día- y anuales -verano e invierno-. La mayor parte de las aperturas de grietas van seguidas de un cierre equivalente, lo que convierte a estas supuestas lesiones en auténticas juntas de dilatación. Pero algunas grietas no retornan, tras el ciclo anual, a su posición de partida: éstas son las que marcan la tendencia en los movimientos de la estructura, siendo la deformada antes estudiada el sumatorio histórico de los pequeños movimientos anuales remanentes.

Los movimientos activos. El gráfico (fig. 8) muestra las tendencias registradas en esos aparatos durante los primeros cuatro años de estudio, entre 1994 y 1997. Se puede ver que son las mismas zonas antes reseñadas: la esquina nordeste del transepto, la nave norte -donde los movimientos son, en todo caso, un tanto erráticos- $y$, sobre todo, el muro al norte de la portada de santa Ana. Así que el edificio parece seguir en la misma dirección que históricamente ha mantenido, a pesar de que es en esas partes donde se han concentrado las obras de refuerzo. Aun sin nuestros sofisticados aparatos, nuestros mayores supieron ver lo que pasaba, aunque quizá no siempre lo vieron claro.

\section{El testimonio del edificio.}

Nos vamos a centrar en tres zonas de la Catedral; y ahora sí vamos a hacer participar a la lectura histórica. Empezaremos por la portada de Santa Ana, visto que es la parte más inestable histórica y actualmente.

\section{La portada de Santa Ana}

Esta espléndida portada se encuentra en el primer tramo sur del transepto, abriendo la Catedral a la plaza de Santa María, junto a una antigua torre de escaleras del muro de cinta más antiguo de la ciudad de Vitoria -a la derecha en la foto-.

Las cargas que actúan en el machón norte de la portada. Empezaremos por un análisis estructural aproximado: pre- 
sentamos una construcción gráfica de las líneas de empujes que podemos usar para representar el descenso de las cargas desde la parte alta del edificio -las cubiertas y las bóvedas que cierran el espacio habitable- hacia el cimiento y el suelo (fig. 9). La construcción gráfica se basa en las leyes de la estática para establecer uno de los posibles estados de equilibrio de las cargas, hipotético e incontrastable como antes dijimos. A pesar de eso, es muy útil porque nos da una visión aproximada de cómo "debería" funcionar la estructura, además de permitirnos comprobar aproximadamente la magnitud de los esfuerzos a que están sometidas las fábricas.

El desequilibrio de las cargas a través de la construcción. Sin embargo, a pesar de que hay un salto imposible de dar entre el cómo debería funcionar y el cómo funciona realmente, hacemos esta hipótesis en la intención de buscar la manera más fácil y directa de transmitir las cargas. Vamos a ver cómo sucesivas obras le han puesto muchas dificultades a esa simple transmisión. En los gráficos detallados se ve que la propia portada supone una distorsión de la dirección de la línea de cargas que desciende desde lo alto de las bóvedas: la línea de empujes debe sortear la jamba de la puerta y desviarse hacia la izquierda del machón.

Pero realmente el machón, que recoge los pesos de bóvedas y cubiertas, viene a descargar más allá de la jamba. Así que el arco de la portada sólo funciona para resistirse a sí mismo y al tramo de muro que cierra la iglesia por encima, pero no para aguantar a las bóvedas y sus empujes, que se conducen por el machón hacia el exterior. Se ven en el dibujo detallado dos vectores negros, uno más a la derecha para las cargas inferiores y otro más a la izquierda para las del machón y las bóvedas. El otro vector, más grande, es la composición de ambos, correcta desde el punto de vista de la estática gráfica que estamos manejando pero incorrecta desde el punto de vista de la transmisión de las cargas, que ha de ser siempre descendente y sumarse "hacia delante". Debemos quedarnos con las dos resultantes menores y analizarlas separadamente.

La construcción como está ahora. En la dirección del descenso de las cargas superiores nos encontramos entonces con dos serios problemas constructivos. Por un lado, la pechina, aparentemente obtenida por vuelos sucesivos, soporta en ménsula la gran masa "flotante" del machón -que se ve en la foto inferior derecha-. Por otro lado, bajo ella, el muro de cierre de la capilla junto a la jamba no es más que un rechapado muy endeble que oculta un relleno inconsistente de cascotes, como luego veremos al hablar de la capilla de los Reyes que se encuentra tras este muro.
El machón de Saracíbar. Este machón inestable, sin embargo, no siempre fue así (fig. 10). De hecho, su construcción es relativamente reciente, de hacia los años sesenta del siglo XIX; y su modificación, de la última restauración, casi exactamente un siglo después. Fue en aquél entonces, hacia 1860, cuando otro arquitecto restaurador, Martín Saracíbar, se hizo cargo de la Catedral, recién consagrada sede episcopal, y acometió una serie de reformas funcionales y estructurales. Debió encontrarse con la gran deformación de la nave del transepto y, obedeciendo a su miedo, trató de ponerle remedio construyendo dos grandes machones en el muro occidental de ambos brazos del transepto. En el plano de la izquierda, debido a él, se ve el gran machón del sur llegando hasta el vano de la portada, que no se representa como tal sino como el paso a una habitación cerrada hacia el exterior. El plano de la derecha, actual de la Catedral, muestra la portada recompuesta y el machón reducido; la habitación ha desaparecido.

El desmontaje del machón. Tras el miedo de Saracíbar vino, un siglo después, el deseo de recuperar la visión de la portada y el acceso a través de ella (fig. 11). En la foto izquierda se ve cómo era el refuerzo de Saracíbar y la habitación que oculta la portada. Luego se desmonta la esquina sur del machón, descarnando su relleno y recomponiendo el esquinazo. Pero se hace de una forma extraña: en la planta y el alzado se ve el corte sesgado -en claro- que elimina la parte que ocultaba la jamba norte; hasta aquí, todo bien, pero se ve también un triángulo, marcado con color más intenso, que representa la parte del machón conservada y, por así decir, descalzada, gravitando sobre la pechina triangular. En el alzado se ve cómo la zona desmontada tiene exactamente la anchura de la jamba. A la derecha se ve el estado actual del machón completo.

Las deformaciones, su proceso bistórico. Hasta aquí, las intervenciones históricas, en las que podemos entender cuáles han sido los motivos de los restauradores - miedo estructural y neogoticismo formal-. Pero necesitamos saber cómo ha respondido la Catedral a cada intervención, pues ésta es la medida de su seguridad. Lo que mostramos ahora presenta una interesante combinación de resultados de los estudios efectuados (fig. 12). Sobre la sección trans-versal del brazo sur del transepto, a través de la portada, se ha remarcado el proceso de deformaciones padecido. En primer lugar, marcado con 1 en el esquema de la izquierda, se ve una gran inclinación del muro debida al empuje de la bóveda y a la existencia en este punto de un contrafuerte sin duda muy esbelto y deformable, no apeado lateralmente por arbotantes y botareles exteriores, como es habitual hacer en la construcción gótica -contrafuerte que debe 
estar todavía embebido en el machón-. Ese giro se produce a partir del punto 2 , donde acaba la rigidez del muro que proporciona el gran espesor de las arquivoltas de la portada. El desplome completo respecto al arranque del muro en el suelo viene indicado en 4. En este estado lo encuentra Saracíbar, que dispone su gran refuerzo, el cual a su vez sufre un pequeño giro ulterior, representado en 5 . Ya la diferencia de giros entre 4 y 5 indica que la fábrica había sufrido un gran giro antes del refuerzo. Pero, ¿cuánto antes?.

Podemos fijarnos en la parte superior del dibujo, sobre 1 , donde se encuentra una sección de muro prácticamente vertical, y que corresponde a un recrecido de las fábricas durante la sustitución de sus cubiertas, mediado el siglo XVII -luego hablaremos más de esto-. Si esta porción de muro se construyó en ese momento y desde entonces casi no se ha inclinado, esto quiere decir que esta parte de la Catedral ya había quedado prácticamente estabilizada, siendo probablemente superfluo el refuerzo decimonónico.

El final de la secuencia lo marca la grieta 6, abierta en los últimos treinta años. El semidesmontaje del machón y, sobre todo, la gravitación de la parte superior restante sobre la eliminada porción inferior, han significado una reactivación de los movimientos, cuyo final no podemos prever.

Estado de agrietamiento y movimientos actuales. En las bóvedas de esa parte se puede ver el resultado, hoy, de estas intervenciones: el muro occidental, sobre la portada, ha girado hacia el exterior y se ha separado de los plementos en el punto de cambio de rigideces relativas, esto es, sobre los arcos formeros. Sin embargo, volviendo al análisis límite, tampoco esto significa que nos encaminemos al colapso. $\mathrm{O}$ al menos no podemos afirmarlo, pues podemos encontrarnos todavía en el periodo de tiempo que una estructura necesita para acomodarse a sus nuevas condiciones de contorno. De hecho, los primeros "cinco minutos" tras el descimbrado ya han transcurrido más que de sobra, y el edificio sigue en pie. Sólo nuestros aparatos de control de movimientos nos alejan de la seguridad de que la estructura es estable.

\section{El cuerpo de las naves}

En otra parte de la Catedral aparecen problemas parecidos que se estudian con las mismas herramientas. Ya vimos que otra zona de inestabilidad histórica es el muro que separa la nave norte de la central (fig. 13).

Los movimientos de los pilares del lado norte. Nos encontramos aquí unos pilares, el cuarto y el quinto de la serie, con unos acusados giros en dos direcciones, hacia el interior de la nave central y hacia la cabecera. En la foto izquierda se ve la composición de desplazamientos del cuarto pilar y de la pilastra sobre él, girada hacia el norte -como ya veíamos en la presentación general de las deformaciones-. En la de la derecha se ve el pilar noroeste del crucero, entre la nave central y el transepto norte. Se acusa en esta perspectiva el doble giro hacia el oeste - derecha de la foto- y hacia la nave -apreciable con el aspecto de un escalonado entre el pilar y la pilastra superior-.

El extraño escalonamiento del triforio. Estos giros de los pilares han provocado una de las formas más atractivas de la Catedral: los escalonados entre tramos contiguos de la balaustrada del triforio (fig. 14). La foto muestra el alzado del muro norte del quinto tramo de la nave central, pero se acusa el mismo escalonado en los cuatro tramos del triforio -dos al norte y dos al sur- que confluyen en los pilares de embocadura de la nave con el crucero.

En la explicación de esos desplazamientos se presentan dos problemas aparentemente distintos aunque con el mismo origen. El primer desplazamiento es un corrimiento en horizontal de la base del triforio que mueve las piezas inferiores de la balaustrada. Las piezas en $\mathrm{T}$ que forman el antepecho giran para acordarse con esos desplazamientos en su extremo inferior, mientras se mantienen en su posición en el nudo con los parteluces, los cuales a su vez se inclinan para asumir el mismo movimiento horizontal en sus extremos inferiores, manteniéndose quietos en sus cabezas, junto a las piezas de los arquillos que quedan retenidas por el muro alto, que no se desplaza. El segundo movimiento es un asiento diferencial del extremo derecho del tramo ahora considerado del triforio, asiento respecto del extremo izquierdo. Ambos movimientos se deben a la apertura del arco diafragma que, bajo el triforio, separa las naves lateral y central. La apertura del arco en sus apoyos sobre los pilares implicará un descenso de su clave central, pero también una pérdida de curvatura del semiarco derecho -el que apoya en el pilar que más se mueve hacia la cabecera-. La suma de estas deformaciones dará el asiento diferencial, mientras que la simple apertura del arco provocará el corrimiento del suelo del triforio y el requiebro de la balaustrada.

Las cargas sobre el pilar del crucero. El interés en este fenómeno tan particular se encuentra en que es otra vez una manifestación de esa capacidad de las fábricas de adaptarse a los movimientos, propios o inducidos desde fuera, sin perder el equilibrio.

Sobre este pilar del crucero -sobre los cuatro, pero especialmente los dos que abren la nave mayor- se encuen- 
tran dos componentes distintas de esfuerzos laterales debidas a los empujes de las bóvedas inferiores y, sobre todo, de los pesos de los muros de cierre elevados que cargan sobre los arcos diafragma (fig. 15). Los dos esquemas de cargas de los detalles muestran cómo esos empujes se dirigen hacia la cabecera en la sección de la izquierda, correspondiente a las cargas de la nave central; y hacia la nave central en la sección de la derecha, con las cargas del muro occidental del transepto. El giro que estos empujes producen en el pilar se combatió históricamente con la introducción de dos arcos codales, uno salvando la nave del transepto -que se ve en la foto- y el otro sobre la nave central -hoy desaparecido-. Esta solución es típica de los refuerzos de época tardía, cuando ya no se entiende bien la elaborada mecánica de empujes de la arquitectura gótica y se recurre a los refuerzos por miedo a que los giros que se detectan conduzcan al colapso. Se encuentran en otras catedrales, de las que podemos citar Tuy y Ávila entre las españolas. Sin embargo, volviendo a apoyarnos en los teoremas del análisis límite, podemos decir que son perfectamente innecesarios, pues los pilares y arcos ya habían dado una respuesta a las solicitaciones asumiendo esas extrañas deformaciones.

Evolución histórica de la estructura. En el análisis de las etapas constructivas efectuado se ha establecido la diacronía existente entre el refuerzo con el arco codal y la arcada lateral. Pero también se ha visto que el tramo donde se encuentra el triforio escalonado se construye en fase anterior a los demás cierres superiores, cuando la Catedral se cubre con bóvedas de madera que imitan a las de piedra.

La sección transversal, conducción de las cargas al cimiento. Ahora bien, en la nave mayor se encuentra otro problema más importante que este del giro de los pilares del crucero (fig. 16). En el anterior tramo desde los pies nos encontramos con un pilar muy inclinado hacia la nave central y, sobre él, una pilastra con un enorme desplome hacia el exterior. El análisis estático de la sección nos enseña por qué se han producido estos giros: en el dibujo de detalle se ve cómo la línea inclinada de descenso de la carga de las bóvedas superiores incide sobre los riñones del arco perpiaño de la nave lateral. Aquí se produce un gran esfuerzo de compresión que provoca un empuje lateral muy grande sobre la cabeza del pilar. La composición de este empuje con los pesos que, en la dirección perpendicular a esta sección, descienden por el mismo pilar -en la sección longitudinal de la nave-, da una resultante muy inclinada y de gran magnitud que desciende sobre la cimentación con una enorme excentricidad. Esta cimentación es de muy pobre calidad, lo cual no significa que no sea capaz de resistir los esfuerzos que la solicitan, sino que es muy deformable debido a la mala ejecución de la mampostería, con grandes juntas de mortero muy plástico y compresible. La excentricidad de la carga hará que la parte del cimiento más solicitada -hacia el centro de la nave- asiente más que la parte exterior -hacia la nave lateral-, provocando, esta diferencia de asientos, el giro de la base del pilar y de toda la estructura sobre él.

Deformación de la sección transversal. Esa deformación se arrastra al resto de la estructura, y se suma a otras más arriba, lo que se muestra en estos gráficos (fig. 17). Atrás vimos que la primera cubierta de la iglesia se hizo con bóvedas de madera. Para levantar los muros en que apoyaban éstas, se reforzaron exteriormente con unos grandes contrafuertes adosados, de gran sección transversal, que vinieron a apoyar sobre los riñones del arco perpiaño inferior -se ven en la foto superior-. Lo cierto es que si estos contrafuertes hubieran sido más esbeltos -menos sobresalientes del muro- las deformaciones habrían sido casi nulas y las bóvedas altas se habrían sustentado con la misma eficacia. De hecho, es lo que sucede en los dos pilares anteriores desde los pies, el que apea el coro y el siguiente, donde no se acusan serias inclinaciones de las pilastras y muros superiores a pesar de soportar pesos y empujes de las mismas magnitudes. Así que tenemos aquí otro error de concepción -otro exceso de refuerzo- que acarrea grandes deformaciones. En efecto, ese contrafuerte viene a provocar una concentración de la carga en el riñón del perpiaño, y los arcos de dovelas son muy sensibles a las cargas puntuales situadas en ese punto, pues rompen la simetría intrínseca de su trazado geométrico. En la foto inferior se ve la pérdida de curvatura que padecen esos arcos, y en el gráfico se explica cómo eso repercute en los movimientos globales. El arco sobrecargado sufre una pérdida de curvatura y esto conlleva un descenso de su tercio central, justo el punto en que apoya el gran contrafuerte. Al descender ese punto de apoyo, mientras el otro lado, que descarga directamente sobre el rígido pilar, no desciende, se produce un giro del contrafuerte que arrastra a todo el muro superior y abre los apoyos de las bóvedas. Éstas se deformarán, perdiendo los arcos perpiaños parte de su curvatura, y resultando la forma torturada que se aprecia al ver la nave mayor desde el triforio.

Los arcos del miedo, construcción y eliminación. Esa composición de deformaciones se acusó, para los antiguos restauradores, sobre todo en el giro del pilar inferior hacia el centro de la nave (fig. 18). Nuevamente, la solución fue la introducción de un arco codal a la altura del encastre de los arcos perpiaños, en la prolongación del pilar. En la foto 
izquierda vemos esos arcos inmediatamente antes de su desmontaje, durante la restauración de los sesenta. A la derecha, el estado de la Catedral en 1996, cuando empezamos a trabajar en ella. Los arcos han desaparecido, sustituidos por unos poco eficientes tirantes metálicos anclados sobre los capiteles de los pilares. Una vez más, el corolario viene a ser una constatación de la capacidad de acomodo de la estructura a las cambiantes condiciones de contorno que los restauradores imponemos; pero no el colapso.

Los arbotantes exteriores. Con todo, en este cuerpo de las naves hubo otra obra de refuerzo para contener el mismo problema: al exterior se dispuso todo un sistema de contrarresto de los empujes de las naves superiores, formado por arbotantes y botareles exteriores, recrecidos sobre la base de otros estribos que se previeron en la traza original de la Catedral pero no se construyeron con ella, seguramente convencidos de que las bóvedas de madera no habían de producir grandes esfuerzos laterales y no necesitaban el contrarresto (fig. 19). Los giros que hemos visto convencieron a otros, más tarde, de la necesidad de esos refuerzos, aunque nosotros volvemos a dudar de su absoluta necesidad: si los giros se producen por la aplicación de grandes esfuerzos descentrados en el cimiento o puntualizados sobre los riñones de los arcos, la componente horizontal de esas resultantes tiene una incidencia sólo parcial: agrava el problema pero no es el problema. En todo caso, si no son necesarios, tampoco están de más; y si eran imprescindibles, ya están ahí construidos. En definitiva, creemos que el refuerzo sí ha sido eficaz, hasta el punto de que tras esta operación, las naves de la iglesia se estabilizaron casi definitivamente.

El testigo-cero del cambio de cubiertas, siglo XVII. Como posible confirmación de esta afirmación, volvemos a un punto ya mencionado antes, el de la sustitución de las cubiertas en el siglo XVII. Las noticias históricas hablan de que en ese momento la Catedral se cubría con un tejado que descansaba sobre unos rellenos inconsistentes dispuestos sobre los cascos de las bóvedas. La crónica sigue diciendo que esa cubierta se elimina para aligerar de peso a las bóvedas, en grave riesgo de colapso, y para disponer otra estructura de madera triangulada, lo que exige levantar sus puntos de apoyo para pasar el tirante sobre las claves centrales de la bóveda, más altas que las de los formeros. En efecto, si superponemos los arcos formeros del interior, sobre los que descansan esos cascos, y el alzado exterior del muro sur de la nave central, podemos observar que la línea de las claves de los arcos coincide realmente con el evidente recrecido del muro con obra de mampostería sobre la sillería antigua, que se aprecia en la fotografía derecha, más pequeña.
Así que podemos concluir que ese recrecido cierra el ciclo de grandes inestabilidades de la Catedral, pues, como ya observamos sobre la portada de santa Ana, el muro nuevo casi no se ha inclinado desde el momento de su construcción. La mayor parte del giro del muro sucede antes de este recrecido, encontrándose por en medio la erección de los arbotantes y estribos exteriores.

\section{Las pequeñas reformas del edificio}

En cuanto a los problemas de equilibrio global de la fábrica, estas secuencias explicadas hasta aquí vienen a representar la historia estructural de la Catedral a grandes rasgos. Los proyectos de refuerzo general, mediante arbotantes y estribos, con arcos codales o machones, vienen a responder a unas deformaciones que, acertada o erróneamente, son entendidas como un riesgo de colapso.

Sin embargo, no todos los que intervienen en la Catedral tienen ese mismo ánimo, y en muchas partes nos encontramos con ciertas obras que, obviamente sin tener esto como objetivo, suponen un debilitamiento claro de la estructura en alguna de sus partes. Acarrean daños locales que, al menos en un punto, la esquina sudoeste del crucero, llegan a ser muy graves y a poner en riesgo gran parte de la estructura. Hablamos de la apertura de ciertas capillas o arcosolios funerarios, siguiendo el deseo de particulares que quieren prolongar su efímera gloria después de su muerte. Las más importantes, por el daño que hicieron, son las capillas abiertas en los primeros tramos de las naves laterales.

La capilla de santa Victoria, cargas y reacciones. En el muro norte se abre la capilla de santa Victoria, poco más que un nicho apuntado en la parte baja del muro de cierre, muro que perteneció al primer recinto amurallado, el primer proyecto de iglesia correspondiente a Alfonso VIII, y sostenía un contrafuerte de gran tamaño que descargaba la bóveda de la nave norte del transepto (fig. 20). Se ve en el diagrama de descenso de las cargas cómo la resultante de esa descarga viene dirigida sobre la capilla. Cuando ésta se abre, esa resultante ha de encontrar un nuevo camino hacia el cimiento, y para lograrlo ha de provocar un grandísimo empuje en la clave de la pequeña bóveda que cierra la capilla, cuya reacción inversa en el arranque de ésta sobre el muro se recompone con el resto de los pesos de la estructura que actúan en este punto, para dar una resultante final de gran inclinación. La existencia en esta parte de un gran muro de cimiento correspondiente a ese magno proyecto de Alfonso VIII es lo que impide que ese esfuerzo provoque un gran desequilibrio del cimiento que hubiera producido mayores deformaciones y, quizá, el colapso. Sin 
embargo, el empuje aplicado en la base de la pilastra que da vuelta hacia el transepto la hace girar desde ese punto y abrirse en una enorme grieta hasta el arco formero de la bóveda. La introducción de un arco codal en la nave del transepto viene a limitar ese movimiento de la pilastra. Es, en este caso, una solución acertada, pues viene a evitar un daño local mediante una prótesis local. Es decir, que si bien estos arcos no tienen gran participación en el equilibrio global, sí la tienen para restablecer el equilibrio local de un miembro concreto, en este caso y en el próximo que ahora veremos. Sujetando a este miembro participan en el equilibrio general, pues éste se vería comprometido si fallara la pilastra.

La capilla de los Reyes, cargas y reacciones. En posición simétrica con la anterior se abre otra capilla, la de los Reyes, aún de mayores dimensiones y con peores, casi catastróficas, consecuencias (fig. 21). En la foto se puede apreciar el arco que daba entrada a la capilla antes de construirse el refuerzo del muro medianero con el transepto. La foto data de la anterior restauración y muestra la capilla abierta tras desmontar el muro de entramado que la cerraba. A la izquierda se ve el espesor del refuerzo del muro del transepto y se acusa la traza completa del arco de medio punto que abría el espacio a la nave lateral, parcialmente apeado en el refuerzo. Si trasladamos esa imagen a la sección con el diagrama de esfuerzos, podremos apreciar que el corte de la línea de empujes se producía más alto que en la capilla antes vista, con lo que el desequilibrio de la resultante en la base de la pilastra del transepto sería aún más acusado.

Sabemos que esta obra provoca graves agrietamientos de la fábrica y que se desencadena un pleito entre los promotores de la capilla y la colegial de la iglesia. El pleito se salda, en Valladolid, con la condena de la capilla, que debe ser desmontada para reparar el daño. Con todo, la iglesia no llegó a caer, mostrando una vez más su capacidad de adaptación.

Las capillas del transepto, avatares. Este fenómeno no es privativo de las naves laterales. En las capillas del transepto también se acometen distintas intervenciones de pequeña entidad pero con repercusiones en la estabilidad del edificio (fig. 22). En la foto inferior aparecen los dos arcosolios que, ya en fase gótica y antes de culminarse la construcción de la iglesia, se abren en el muro medianero de las capillas orientales del transepto sur. En la foto central se puede ver una puerta abierta en el muro simétrico del anterior, entre las capillas del transepto norte, para dar acceso a la capilla del extremo noreste desde esta parte de la girola, pues esta capilla se cierra para usarla como sacristía tras el ascenso de la iglesia a sede catedralicia. Esta puerta es cerrada nuevamente en la restauración, cuando además se enmascara la reparación imitando la sillería del muro antiguo sobre el nuevo estucado -como se ve en la foto derecha-.

Las cargas en las capillas del transepto. Estas capillas y puertas supondrán también acomodos de la fábrica. En los diagramas de cargas que pasan por esos muros se puede ver y comparar el efecto que produce la apertura de los vanos. En todos ellos se aprecia el mismo efecto explicado en la capilla de santa Victoria: la formación de un arco de descarga sobre los dos enterramientos y la fuerte inclinación y excentricidad que adquiere la resultante en la pilastra que da a la nave del transepto, resultante que nuevamente se mantiene dentro de la sección eficaz de la fábrica gracias a que el muro de cimentación aumenta su espesor en la parte inferior. Al otro lado, sobre el muro de cierre exterior, también se produce un gran empuje lateral que a duras penas se contiene en la sección resistente del muro de cie-rre exterior, a pesar de su gran espesor y por culpa de la gran altura que salva hasta el nivel del terreno en el exterior.

Agrietamiento de las capillas del transepto. Como hemos visto, en el lado norte también se interrumpió durante un tiempo el correcto descenso de las cargas. Entonces aparecieron grietas similares a las presentes sobre la capilla de santa Victoria, marcando el desgajamiento de la pilastra respecto al muro medianero, así como el giro del muro exterior, también debido a la aplicación del empuje en la base del mismo. El cierre de la puerta y la recomposición de la consistencia del muro permitieron enmascarar estas grietas y que no volvieran a abrirse tras la restauración. Las que ahora mostramos en nuestras fotos han sido recuperadas por nosotros en la investigación efectuada. Son por tanto grietas no activas, como corresponde al momento de la secuencia histórica en que nos encontramos, con los vanos del muro cerrados y los empujes descendiendo de manera "natural" hasta el cimiento.

Capilla de santa Victoria, equilibrio conseguido finalmente. Esa misma recomposición fue posible efectuarla en la capilla de santa Victoria. Cuando se empieza la restauración, el frente de la capilla presenta el aspecto que refleja la foto izquierda de la figura 20, donde no se aprecian fisuras en el paramento junto a la pilastra de esquina. Sin embargo, se puede apreciar que la capilla está revestida hacia el exterior con un muro, recrecido frontalmente sobre la fábrica medieval y rematado con una cornisa que hace el retranqueo hacia el paño original. En la restauración se desmonta ese revestimiento y, casi sin duda, se encuentra el paño del muro agrietado como se muestra en la foto izquierda de la figura 4. La restauración restaña la grieta y deja el 
paramento medieval visible pero repasado con estucados imitando sillería para ocultar las heridas ya cerradas, heridas que ahora volvemos a ver -insistimos- por obra de nuestras investigaciones históricas y estructurales.

Capilla de los Reyes, daños recientes e inestabilidad. Sin embargo, en el otro lado, las cosas no están tan bien (fig. 23). El daño que causó la capilla de los Reyes fue mayor y, sobre todo, la reparación fue peor. A la izquierda se pueden ver distintos aspectos del interior de la capilla: en primer lugar, en la foto grande izquierda, se ven los restos de los arranques de los arcos y bóvedas que la cubrían y que hubieron de ser desmontados para reparar la iglesia, y la pobre solución de cierre de los vanos en el muro del fondo de la capilla, que se corresponde, al exterior, con el rechapado de la jamba norte de la portada de santa Ana tras el desmontaje del machón, el punto por el que descienden las cargas de la parte alta de éste y de las bóvedas que apean; en la foto de abajo se aprecia un aspecto más preocupante: el refuerzo del muro medianero con la nave del transepto -cuyo espesor se ve en la foto de la figura 21- se ha cimentado sobre un relleno de arcillas "artificiales" que se encuentra cubriendo al muro de cimentación del primer cierre occidental del transepto, de época de Alfonso X. La pérdida total de la memoria de este muro hizo que los restauradores de la capilla -sus destructores, más biencreyeran que ya habían encontrado firme al descubrir ese relleno de arcillas, sólo a medias compactadas y por tanto muy deformables. Por último, en la foto grande derecha vemos el aspecto del muro medianero de la capilla desde la iglesia: en la foto de la figura 21 se veía el refuerzo del muro medianero mediante un recrecido cosido a ella por llantas metálicas, que se acusan en el frente lateral. Es este refuerzo del muro el que se encuentra mal cimentado. En esta foto grande se ve el anclaje de otras llaves de atado similares con el muro medianero del transepto, con una técnica que denota una ejecución relativamente reciente, de la segunda mitad del siglo XIX o de la primera parte del XX. En todo caso, el problema más inquietante es el que se muestra en la foto derecha superior, en la que se ve la pilastra de esa esquina entre el transepto sur y la nave lateral. En ella aparece una fisura de componente vertical que parece indicar que el forro de sillería está sobrecargado y cercano al fallo local, debido seguramente a que el asiento del muro reforzado ha dejado a la pilastra soportando, sin ayuda, unas cargas muy fuertes.

\section{Conclusiones: la evolución de las fábricas en el tiempo}

Para concluir, tenemos que hacer algunas consideraciones sobre la evolución de las fábricas en el tiempo (fig. 24).
Comenzamos la presentación con las teorías de los estados límite y fijamos en quinientos años el tiempo de vida de una estructura que hubiera traspasado el umbral de una generación en que habría encontrado un equilibrio con el asiento en el terreno. Ahora debemos explicar cómo transcurren esos quinientos años, durante los que los materiales se degradan por la acción de la naturaleza mientras los edificios se ven sometidos a mayores solicitaciones debidas al uso cada vez más multitudinario que se hace de los monumentos. El gráfico del profesor Franco Mola, del Politécnico de Turín, muestra esas dos componentes mediante la curva ascendente inferior, que representa el incremento de las solicitaciones. Las sucesivas curvas superiores, descendentes, representan los procesos naturales de degradación de los materiales. Y los saltos hacia arriba de esa curva vienen a representar el efecto beneficioso que tienen las distintas restauraciones -supuesto que así sea siempre, beneficioso y no dañino, como hemos podido ver-. Lo cierto es que todos los edificios sufren este proceso, y que podríamos particularizar la gráfica para el caso concreto de la Catedral de Vitoria, indicando sobre la escala de tiempos los momentos en que se acometen reformas, tanto las que mejoran como las que estropean la estructura -de las que hay muchas en Vitoria-, y confiriendo a la degradación de las fábricas una pendiente, aunque ésta es muy difícil de evaluar. Nunca sabremos lo cerca o lejos que estamos del colapso final del edificio, aunque podemos creer que la teoría de estructuras basada en los estados límite nos da la tranquilidad de que, puesto que hemos encontrado una situación de equilibrio, el edificio también lo hará. Y el edificio, hasta ahora, no nos ha defraudado en esto. En distintos momentos ha venido a ser restaurado con refuerzos -como los arcos codales y los machones decimonónicosque han supuesto un incremento de su seguridad -aun cuando los creamos en parte superfluos-. La degradación de las fábricas y algunas dudosas intervenciones históricas -que vendrían a representarse en el gráfico como inflexiones negativas, hacia abajo, de la curva de evolución- conducen al edificio a un colapso en un plazo absolutamente impredecible. Nuestra responsabilidad como restauradores es intentar que la próxima inflexión sea positiva.

Sin embargo, nuestros conocimientos actuales nos alejarán bastante de las soluciones de refuerzo típicas en la cultura de la llamada "consolidación estructural", pues las teorías que manejamos dan un margen de confianza muy grande a los edificios que han sido capaces de mantenerse en pie tantos siglos, aun con las complicadas aventuras que ha padecido la Catedral de Vitoria. Además, creemos que una estructura antigua tiene tanto valor como una obra de 
arte de cualquier clase: representa una forma de pensamiento ya perdida que hoy no podemos reproducir y, por tanto, no puede ser destruida por una consolidación que altere la mecánica de su comportamiento estructural, tergiversando su significado. La introducción de materiales y sistemas constructivos de alta rigidez, tales como cosidos de muros alzados, zunchados de sus cabezas y de los arranques de sus bóvedas, encamisados de sus plementerías y tantas otras, destruyen esa capacidad de adaptación que hemos mostrado y que las hace tan perdurables, además de falsear su comportamiento estructural y la memoria que éste supone de aquél pensamiento constructivo desaparecido. No podemos aplicar a estas estructuras un concepto moderno de resistencia, ni siquiera uno de seguridad basado en la limitación de las deformaciones bajo ciertas condiciones de carga; porque no es ese el criterio con el que se construyeron y gracias al cual se mantienen en pie. Los ingenieros del siglo XVIII todavía sabían muy bien cómo se comporta un arco de dovelas y la necesidad que tiene de no ver coartada su capacidad de formar rótulas en distintas partes, en función de los cambiantes estados de cargas a que se ve sometido. Hemos de recuperar ese sentido en las obras de restauración actuales.

La Catedral de Vitoria se encuentra ahora en uno de esos procesos de restauración, y hasta el momento nos hemos limitado a introducir pequeños mecanismos controlados de seguridad, inactivos en todo momento y dispuestos a entrar en acción si el edificio sufre cualquier movimiento brusco debido a las obras que en él vamos a hacer para su recuperación. Son posiblemente refuerzos dictados por el mismo miedo que históricamente ha aquejado a los restauradores, pero no estamos modificando con ellos el comportamiento de la estructura, al menos por esta vez. La Catedral, por su parte, nos recordará siempre todo aquello por lo que ha pasado en su larga vida, ya de ocho siglos. Tendremos que prestar atención a las huellas que nos ha dejado antes de intentar arreglar lo que en buena parte seguramente no necesite arreglo. Este artículo quiere mostrar una manera de atender a esa demanda, mostrando que siempre es posible recuperar la memoria. 


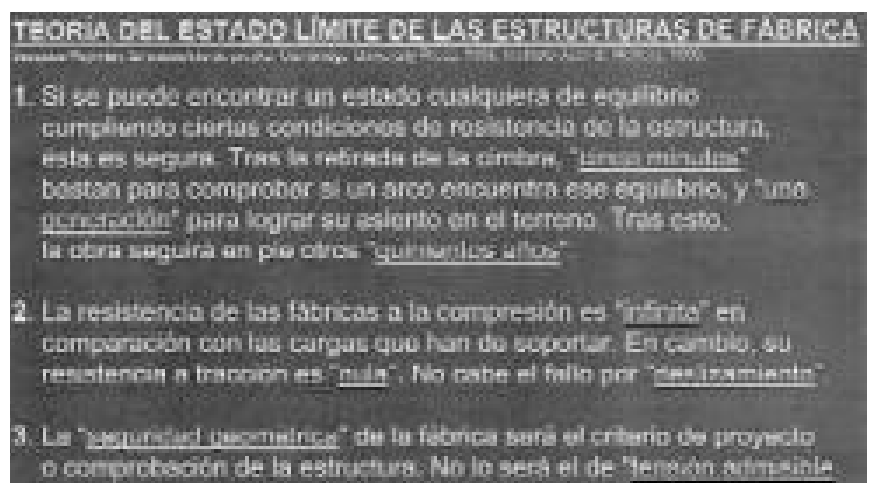

Fig. 1

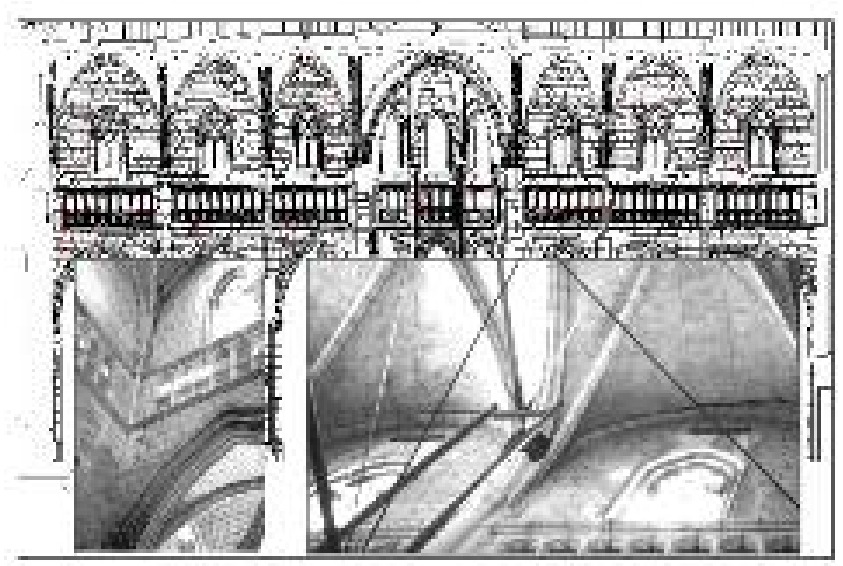

Fig. 3
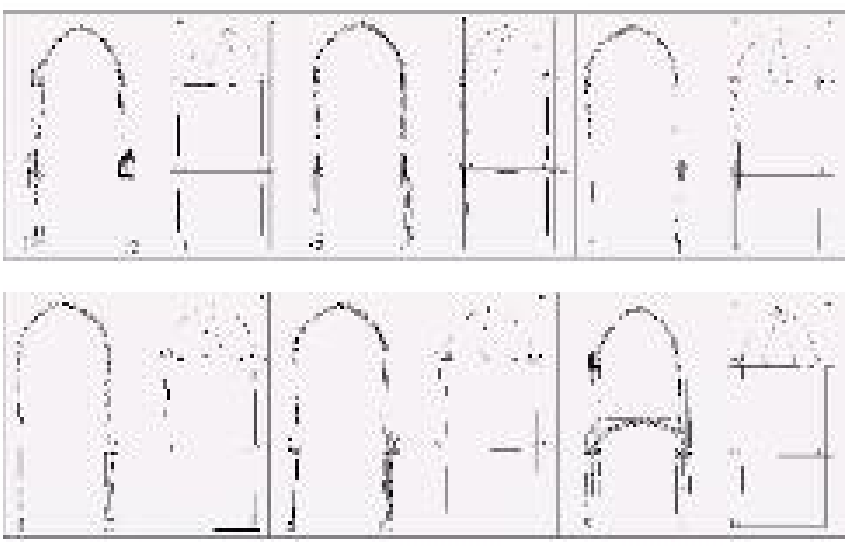

Fig. 5

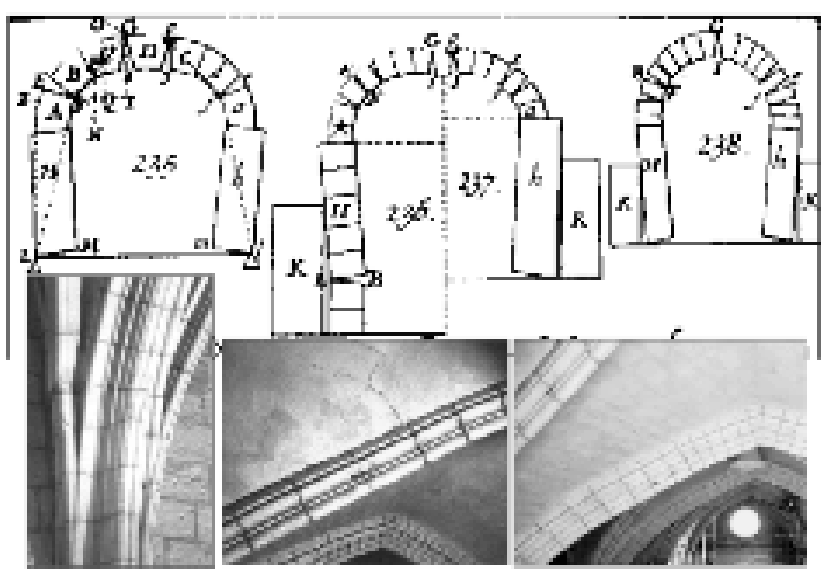

Fig. 2

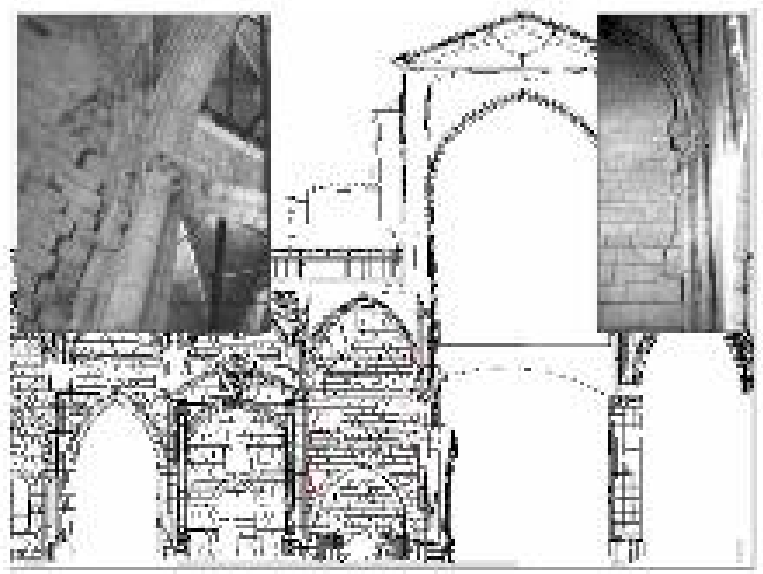

Fig. 4

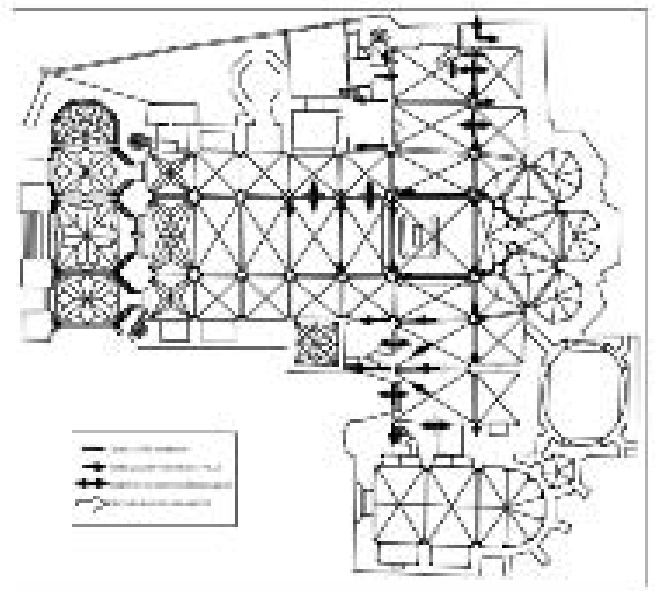

Fig. 6 


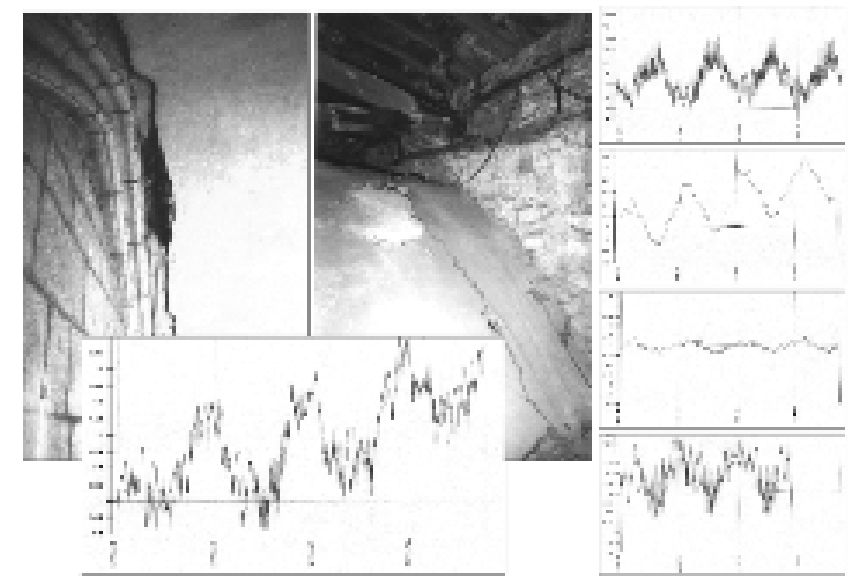

Fig. 7

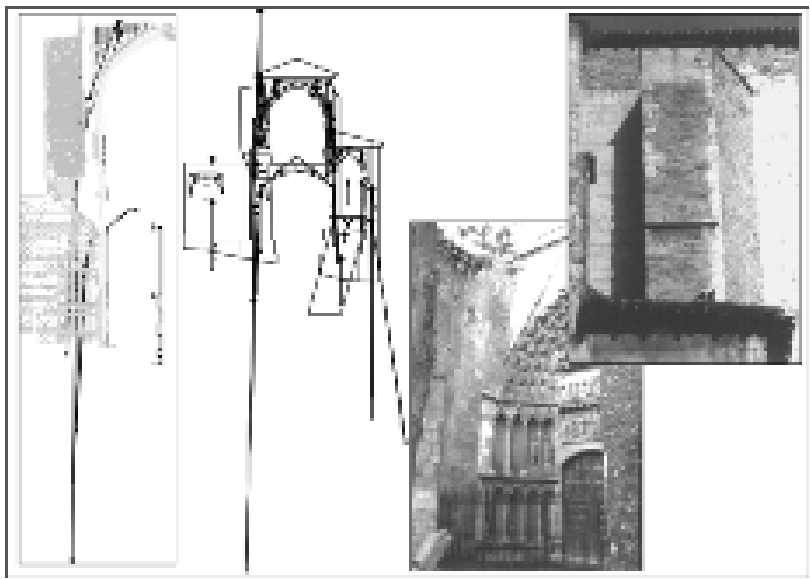

Fig. 9

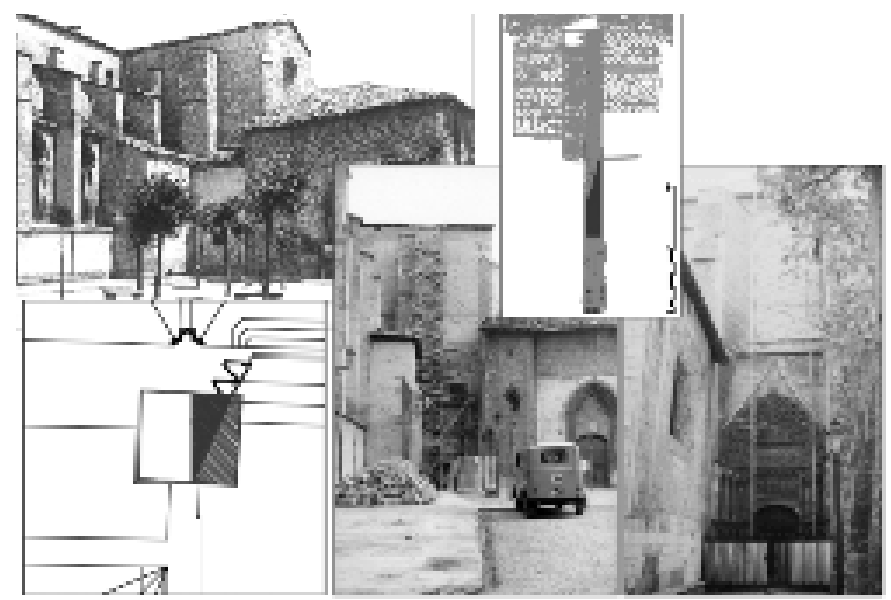

Fig. 11

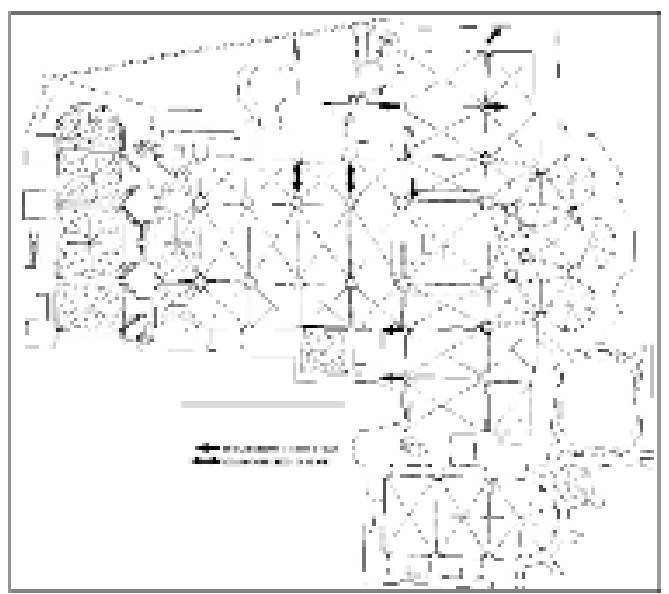

Fig. 8

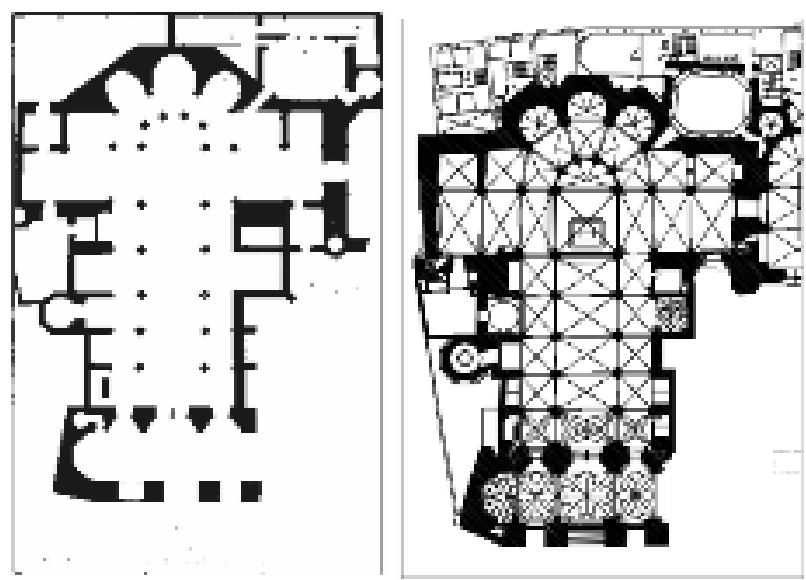

Fig. 10

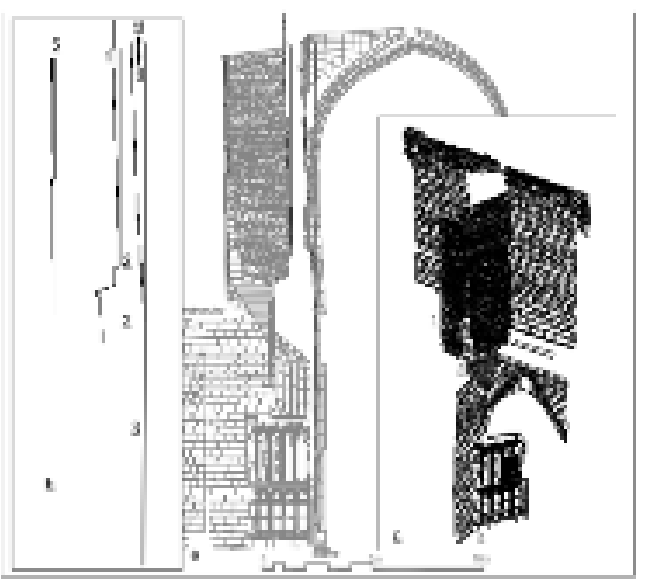

Fig. 12 


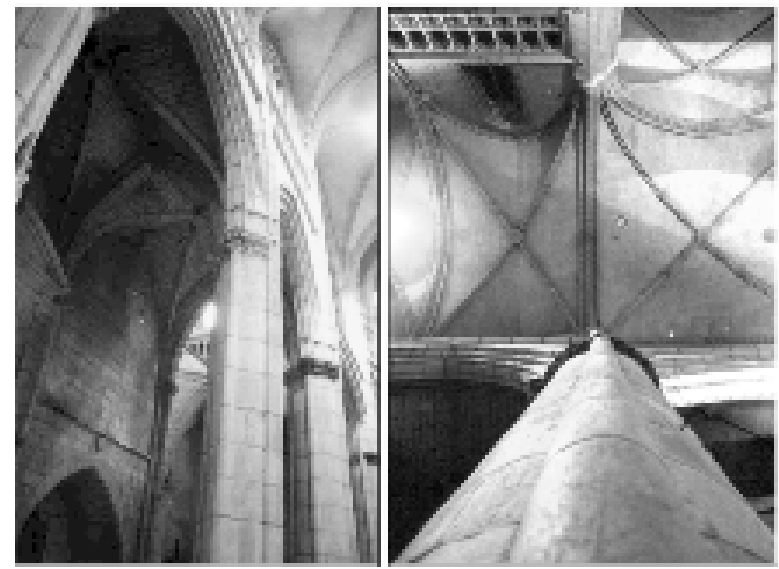

Fig. 13

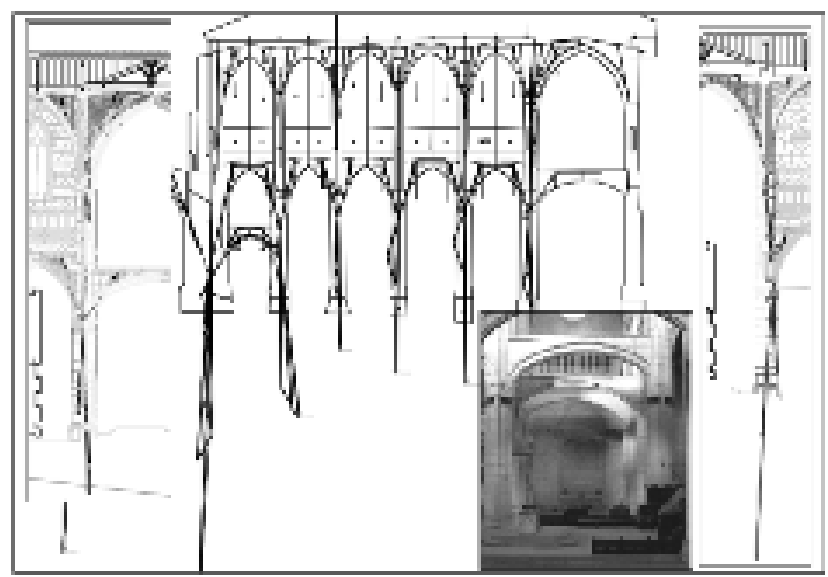

Fig. 15

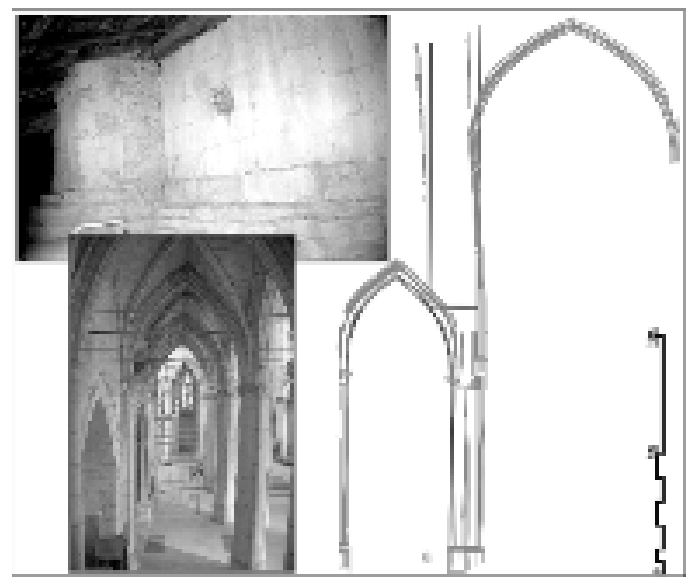

Fig. 17

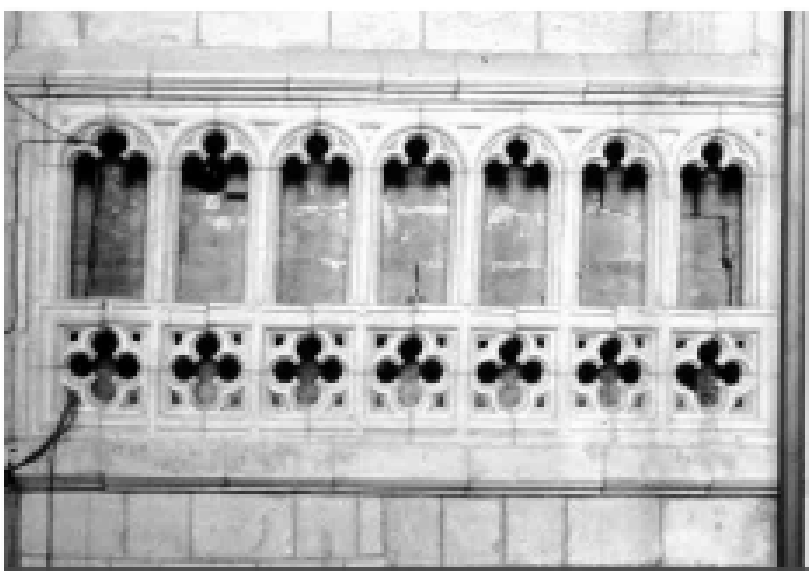

Fig. 14

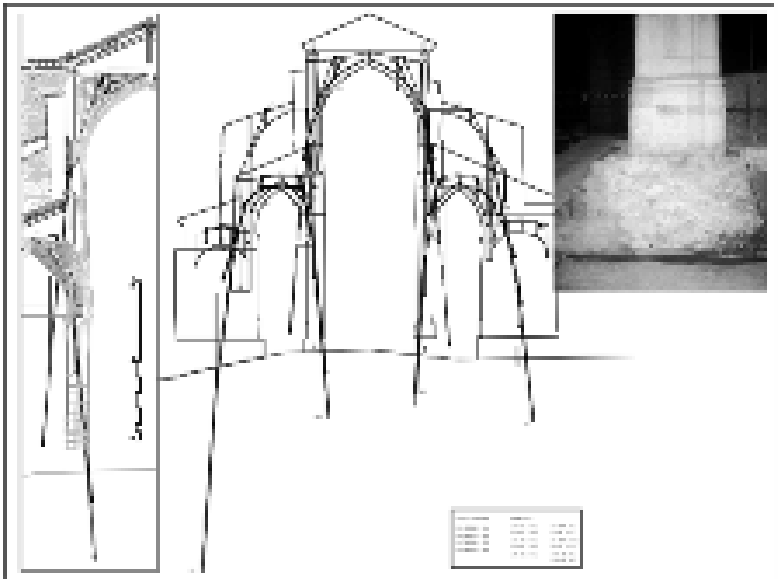

Fig. 16

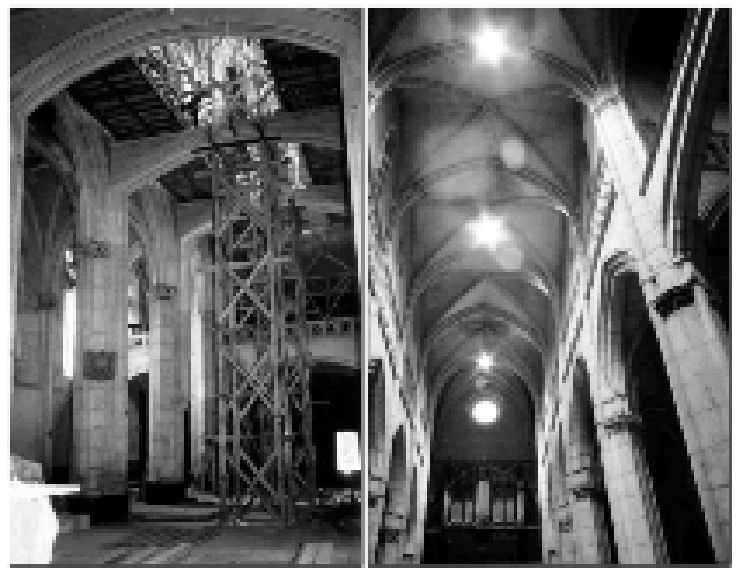

Fig. 18 


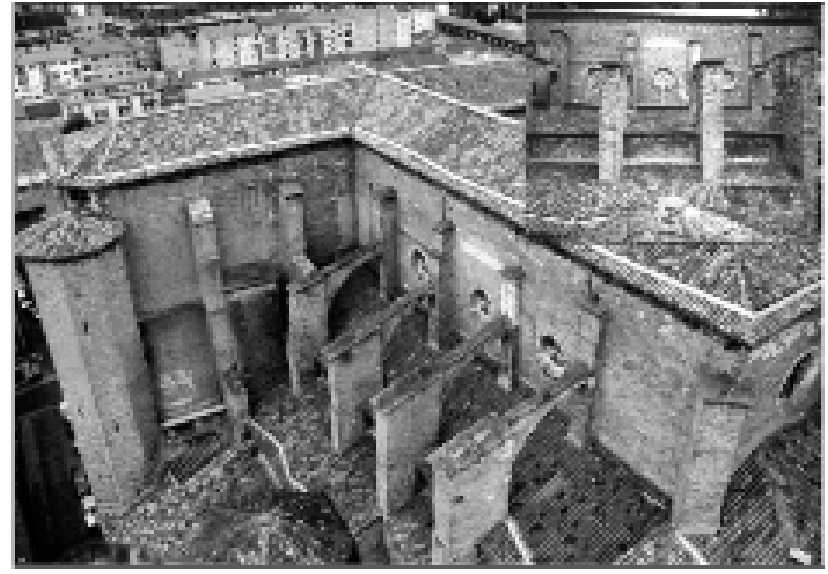

Fig. 19

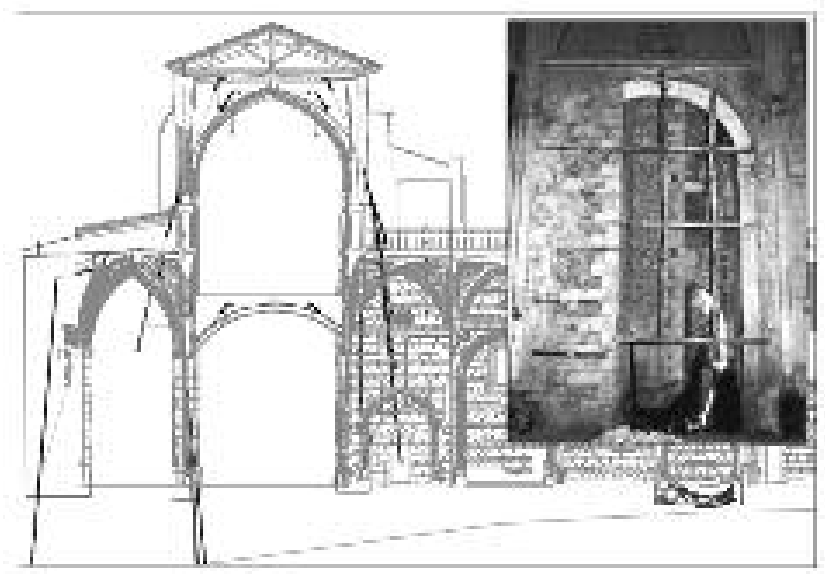

Fig. 21

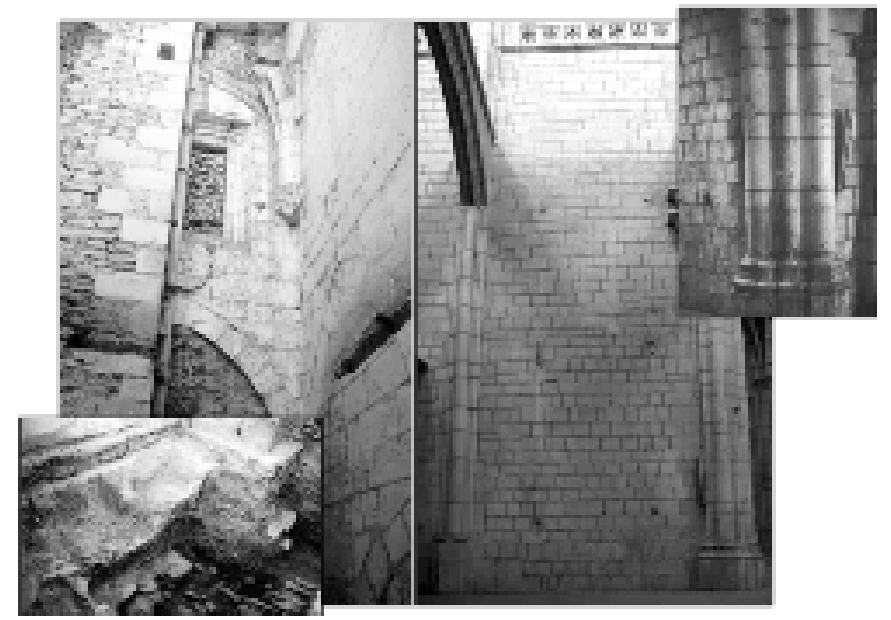

Fig. 23

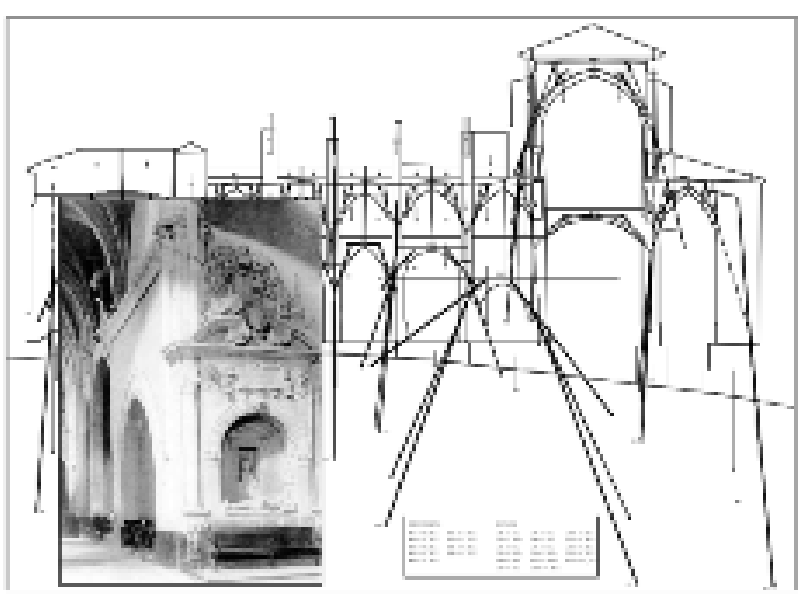

Fig. 20

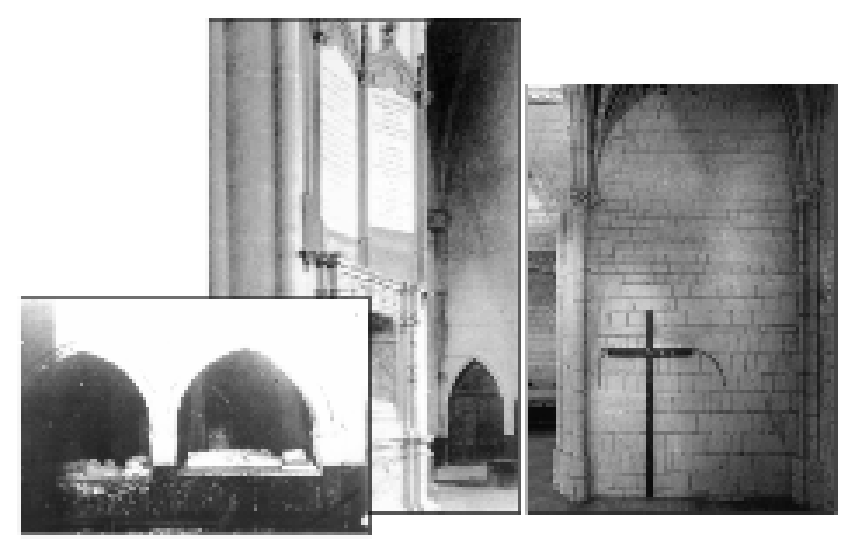

Fig. 22

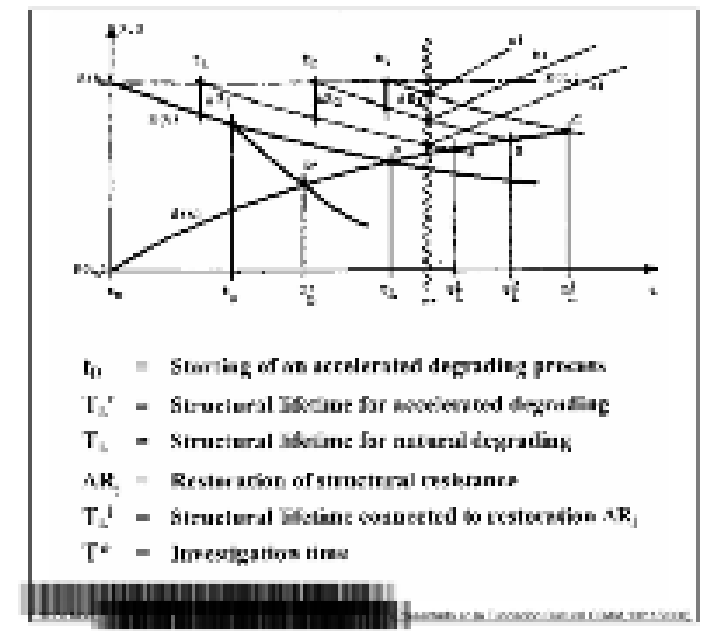

Fig. 24 